\title{
THE BASIC RELATIONSHIP OF ORTHODONTIA AND PERIODONTIA
}

\author{
By PAUL R. STILlMAN, D.D.S., New York City
}

(Read before the National Dental Association, Milwaukee, Wisconsin, August 15-19, 1921)

$\mathrm{F}$

OR many years the orthodontist has been intent upon the correction of malocclusion. On the other hand the periodontist has been intent upon the cure of disease in the investing tissues of the teeth. The former specialty, under the guidance of Angle, has sensed the part they are playing in the prevention of dental and periodontal disease. Black has also called attention to the importance of orthodontia as a preventive of disease.

The late developments in periodontia have now brought us to the point where we recognize derangement of the occlusion as one of the most important factors in the causation of dental periclasia. And we further are finding that our efforts to effect a cure of this condition are of little avail, unless the deranged occlusion can be correctly rearranged. The periodontist now bases his pathology upon disturbance of function, thereby bringing his conception of pathology into harmony with the accepted pathology of other parts of the body. All honor to Angle and Black who also built better than they knew. Their conception of the part which orthodontia would one day play, in preserving the health of the mouth, was prophetic.

It was my pleasure to observe the modus operandi of this section, at the meeting held in New Orleans two years ago, as well as at Boston last summer. It was observed that when a paper on orthodontia was to be presented, the orthodontists flocked in and the periodontists flocked out. Also, when a periodontia paper was in order the audience consisted chiefly of periodontists. We appreciate the fact that many papers in orthodontia deal with problems which appear to the periodontist as having but little of interest for him. Likewise the orthodontist may, on the face of it, seem to find little in the periodontia papers which will be thought to be of value. However at the New Orleans meeting my belief in the fundamental interdependency of these two specialties, impelled me to attend the entire program of this section. It was a pleasure to find that a periodontist could learn just as much from the papers on orthodontia, as from those dealing with his own specialty. It may not be amiss to state, that because of recent developments in periodontia dealing largely with the subject of occlusion, the orthodontist should likewise find much in interest and of practical value to him, in periodontology. The orthodontist whenever he treats a case is at once dealing with potential 
disease; frequently with actual incipient disease of both the hard and soft tissues. His interest in prophylaxis is of the instant, from the standpoint of his case as well as for self-protection. He must be alert, and his efforts directed toward the future as regards the continuing health of the patient's mouth.

It may startle some of the orthodontists present, if the statement is made, that the orthodontist may learn something of value on the subject of occlusion, as well as prophylaxis, from the periodontist. Nevertheless I believe this to be a fact. Dentists have presented themselves at periodontic clinics, and have made the statement, that well known orthodontists have passed upon their mouths as exhibiting a normal occlusion. Yet in these mouths have been observed gross departures from normal occlusion, with an accompanying inco-ordination of function. And these same mouths have exhibited definite symptoms of incipient, as well as advanced periodontal disease.

In prophylaxis, no branch of the dental profession has the power to accomplish so much as has orthodontia. Its mission to humanity is the establishment of dental function and the prevention of disease. It is an established fact, that health depends chiefly upon normal function. Without orthodontia, health would be an impossibility in the mouths of many individuals; since in the absence of normal occlusion, dentistry is powerless to accomplish satisfactory results. The field of the orthodontist is not, however, limited to the mouth alone. We all know the influence which health or disease in the mouth has upon the rest of the body. To maintain the health of the oral tissues is a big factor in the prevention of general disease, and it is a service to the patient whose influence will be felt thruout life.

The orthodontist, in addition, has a more direct opportunity. The large majority of his patients present for treatment during the years of rapid development, and at an impressionable period of their lives. Then the inherent desire for health may be fostered most readily, and the ideaIs of correct living may be readily instilled. The orthodontist who has the spirit of the physician and who is not completely absorbed in the technic of his art, will avail himself of this golden opportunity to serve the future rulers of this nation.

Like the orthodontist, the periodontist is vitally interested in the biologic problems of the tissues around the teeth. They must remove the causes of disease before any return to health is possible. But even after this has been accomplished, in many instances, steps must be taken to arouse nature's regenerative impulses, before he may obtain satisfactory results. And it is in the field of biology that he may learn much from the orthodontist. For investigators in orthodontia have recognized the fact, that results in movement were frequently out of all proportion to the amount of force employed. Their studies have lead them far into the study of the stimulation of biologic impulses and of cell activity. We periodontists may very profitably study with them the design and application of the various appliances they use, since these have quite as much effect in arousing tissue stimuli, as have our own present day methods, their biologic reactions. We need to know more of the physiologic principles involved in natural retention, together with a more definite mechanical knowledge of the appliance used for stimulating this desideratum, The stabilization of teeth which have 
long been out of occlusal co-ordination, presents a problem which can only be solved by the combined efforts of the orthodontist and periodontist.

Another problem for whose solution the combined efforts of the periodontist and orthodontist is required, is the restoration of normal occlusion in those mouths already subject to advanced periodontal disease. It has already become necessary for the periodontist to seek orthodontic treatment for these cases. And this treatment has been found to be practicable as well as beneficial, even after middle life. Contrary to natural expectation, the correct application of force to teeth having deep periclasial pockets, does not cause irritation, as might be expected, but on the other hand, by reason of its stabilizing effort on the teeth, it stimulates an impulse toward the health of the supporting tissues. This is quite logical in the final analysis, for the influence which produces a biogenetic impulse in the healthy tissues of the adolescent should also produce a similar stimulating effect when applied to the adult tissues, even when these tissues are affected by disease.

Permit me this opportunity therefore, to urge upon the orthodontist a deeper interest in the problems presented in the adult mouth. $\mathrm{He}$ may in this way broaden still further the great field in which he is already devoting himself, and at the same time it will extend more widely the scope of the periodontist's services.

These are but a few of the thoughts called forth by this association of our two specialties in this section. The future lies before us as the earth to the miner. An untold wealth of knowledge still remains to be uncovered, and we must dig. Countless additions to science lie just beyond the veil of tomorrow. Shall we not unite more definitely those forces fortuitously brought together and without combined strength set ourselves to the task of wresting from nature the wealth of knowledge which she holds in store for us? 